\title{
Numerical Investigations on Heat Flow of Nanofluids in Ribs Tube Configurations
}

\author{
Sami D. Salman* Ramzi Ata Abd Alsaheb** \\ *,** Department of Biochemical Engineering/Al-khwarizmi College of Engineering/University of Baghdad \\ *E-mail :sami.albayati@gmail.com \\ **E-mail: ramzi_eng_1981@yahoo.com
}

(Received 20 June 2017; accepted 24 July 2017)

https://doi.org/10.22153/kej.2017.07.002

\begin{abstract}
In this paper presents two dimensional turbulent flow of different nanofluids and ribs configuration in a circular tube have been numerically investigation using FLUENT 6.3.26. Two samples of $\mathrm{CuO}$ and, $\mathrm{ZnO}$ nanoparticles with $2 \%$ v/v concentration and $40 \mathrm{~nm}$ as nanoparticle diameter combined with trapezoidalribs with aspect ratio of $\mathrm{p} / \mathrm{d}=5.72$ in a constant tube surface heat flux were conducted for simulation. The results showed that heat flow as Nusselt number for all cases raises with Reynolds number and volume fraction of nanofluid, likewise the results also reveal that $\mathrm{ZnO}$ with volume fractions of $2 \%$ in trapezoidal ribs offered highest Nusselt number at Reynolds number of $\operatorname{Re}=30000$.
\end{abstract}

Keyword: Heat transfer augmentation, Friction factor, Thermal performance factor, Ribs configuration, CFD simulation, Fluent.

\section{Introduction}

Heat exchangers as convective heat transfer equipment are widely used in various engineering applications. Heat rate enhancement in all types of heat apparatus is one of the great significance for the industry. Besides the energysaving, it also leads to minimize the size and weight. In general, the enhancement techniques may be categorized into two kinds; first one is the active techniques which required an external power and second one is the passive techniques which do not required an external power source. Several attempts on heat augmentation techniques using roughen surfaces or tabulators such as groove and rib to disturb the flow and break the thermal boundary layer and consequently increase the heat transfer coefficient. Different configuration of channels with ribgrooves had been investigated in the antecedent decades considering different combinations of the ribs configurations and temperature gradients.

The ordinary ribsgeometries including circular rectangular, square and triangular, all these geometries of channels with rib-grooves were utilized in various engineering applications; gas turbines heat exchanger with cross-flow, aircooling system and gas cooled nuclear power reactor [1]. On the other hand, Nanofluidsas heat transfer enhancement technique has bring significant interesting the past years as applicable and alternative coolants for many fields such as power generation, automotive electronics, air conditioning and nuclear applications [2]. Different types of nanoparticles have been utilized for nanofluid preparation, including metals such as silver $(\mathrm{Ag})$, copper $(\mathrm{Cu})$, gold $(\mathrm{Au})$, and also metal oxides such as $\mathrm{Fe}_{3} \mathrm{O}_{4}, \mathrm{TiO}_{2}, \mathrm{CuO}$ and $\mathrm{Al}_{2} \mathrm{O}_{3}[3-9]$. Due to their sufficient low cost, metal oxides are more enticing for heat transfer augmentation applications compared to metals. Simultaneously, nanofluids were combined with other heat transfer enhancing techniques [10, 11, and 12].

Ahmed et al. [10], reported numerical simulation of the heat and friction characteristics of Copper/water nanofluid with various volume 
fraction range (0 to 0.05)through isothermally heated corrugated channel under laminar flow condition ( $\mathrm{Re}=100-1000)$.It was found that the heat transfer augmented as nanoparticle volume fraction of increases. Likewise, the pressure drop somewhat increases with the volume fraction increases, for all Reynolds number. In addition, the highest value in heat transfer enhancement was obtained at $\mathrm{Re}=200$ and $5 \% \mathrm{v} / \mathrm{v}$ nanoparticle with $43.9 \%$ enhancement compared with base fluid. Mohammed et al. [11], has conducted numerical study on the turbulent heat transfer and friction factor of different nanoparticles $\mathrm{CuO}$, $\mathrm{Al}_{2} \mathrm{O}_{3}, \mathrm{ZnO}$ and $\mathrm{SiO}_{2}$, with different concentration $(1 \%$ to $4 \%)$ and different nanoparticle size (25 $\mathrm{nm}$ to $80 \mathrm{~nm}$ ), with different base fluids (glycerin, water, engine oil) in channel with rib-groove. Their results showed that $\mathrm{SiO}_{2}$-glycerin produce highest Nusselt number followed by $\mathrm{SiO}_{2}$ - engine oil while $\mathrm{SiO}_{2}$ - water produce the lowest value of Nusselt number.

Salman et al. [12] reported a numerical simulation on heat transfer enhancement of nanofluids in circular micro tube using different nanoparticles $\mathrm{CuO}, \mathrm{Al}_{2} \mathrm{O}_{3}, \mathrm{ZnO}$ and $\mathrm{SiO}_{2}$, with different concentration (1\% to $4 \%$ ) and different nanoparticle size $(25 \mathrm{~nm}$ to $80 \mathrm{~nm}$ with ethylene glycol base fluid. Their results showed that $\mathrm{SiO}_{2}$ nanoparticles with particle size (dp) of $25 \mathrm{~nm}$ and particle concentration $4 \%$ at $\mathrm{Re}=1500$ gives the highest value of Nusselt number. It is evident from the recent studies that the simultaneous use of turbulators with nanofluids efficiently gives further improvement in heat transfer rate as compared with the individual uses of nanofluids or of ribs configuration. In the present research the effects of two types of nanoparticles; $\mathrm{CuO}$ and $\mathrm{ZnO}$ with $2 \%$ volume fractions and nanoparticles size of 40nmwith Reynolds number ranging from 10000 to 30000in constant tube surface heat flux with trapezoidal ribs configurations have been investigated numerically.

\section{Numerical Model}

\subsection{Geometry Model and the Governing Equations}

Two dimensions of governing equations have been used to characterize the fluid flow and heat transfer in the circular tube with different ribs configurations as shown in Figures1a-b.The diameter of tube $\mathrm{d}=10 \mathrm{~mm}$ and length of rib tube $\mathrm{L}_{2}=100 \mathrm{~mm}$ and the high and width of ribs is $\mathrm{H}=1.2 \mathrm{~mm}$ and $\mathrm{W}=1.2 \mathrm{~mm}$ respectively. The pitch of ribs is $\mathrm{P}=10 \mathrm{~mm}$.the entrance tube length $\mathrm{L}_{1}=50 \mathrm{~mm}$ in order to achieve the fully develop flow in the tube.

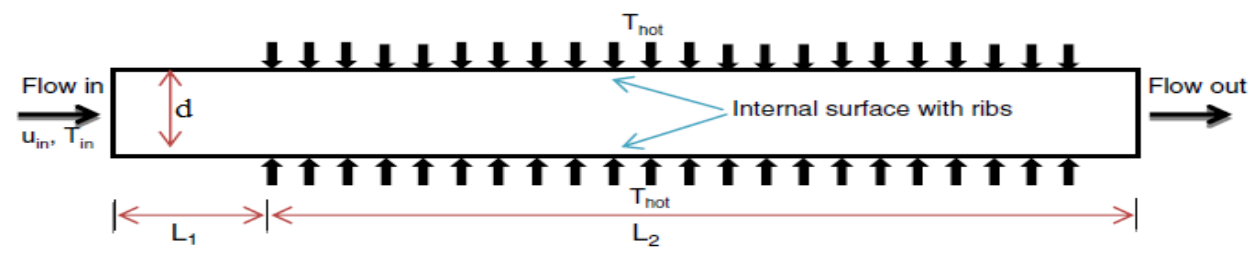

(a)

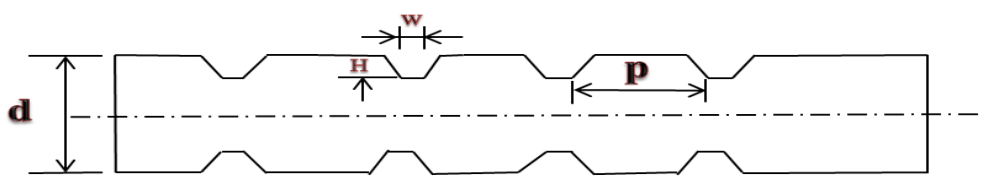

(b)

Fig. 1. Schematic diagram of (a) Tube geometrical model, (b) Trapezoidal ribs.

The assumptions below have been adopted for numerical simulation: (i) Nanofluid is considered as Newtonian and incompressible fluid, (ii) Flow is turbulent, (iii) Heat flux is constant with negligible radiation effects (iv) Nanoparticles is regarded as spherical shape and nanofluid is used as single phase model (v) The rmophysical properties of nanofluidsare considered as constant values. The governing equations in Cartesian form are illustrated as follows [13]:

Equation of Mass Conservation: 


$$
\frac{\partial u}{\partial x}+\frac{\partial v}{\partial y}=0
$$

Equation of momentum Conservation:

$$
\begin{aligned}
& u \frac{\partial u}{\partial x}+v \frac{\partial v}{\partial y}=-\frac{1}{\rho_{\text {eff }}} \frac{\partial p}{\partial x}+\mu_{\text {eff }}\left(\frac{\partial^{2} u}{\partial x^{2}}+\frac{\partial^{2} u}{\partial y^{2}}\right) \\
& u \frac{\partial u}{\partial x}+v \frac{\partial v}{\partial y}=-\frac{1}{\rho_{e f f}} \frac{\partial p}{\partial y}+\mu_{e f f}\left(\frac{\partial^{2} v}{\partial x^{2}}+\frac{\partial^{2} v}{\partial y^{2}}\right)
\end{aligned}
$$

Equation of Energy Conservation:

$$
u \frac{\partial T}{\partial x}+v \frac{\partial T}{\partial y}=\frac{k_{e f f}}{\rho_{e f f} C p_{e f f}}+\mu_{e f f}\left(\frac{\partial^{2} T}{\partial x^{2}}+\frac{\partial^{2} T}{\partial y^{2}}\right)
$$

\subsection{Simulation Boundary Conditions}

Various inlet velocities in the tube with constant temperature $(\mathrm{T}=300 \mathrm{~K})$ and constant heat flux $\left(200,000 \mathrm{~W} / \mathrm{m}^{2}\right)$ were used for simulation.

\subsection{Nanofluids Thermophysical Properties}

The physical properties of nanofluids for $\mathrm{CuO}$ and $\mathrm{ZnO}$ nanoparticles are estimated using the following equations [14] and [20]:

$$
\begin{aligned}
& \rho_{n f}=(1-\varphi) \rho_{f}+\varphi \rho_{n p} \\
& (\rho C p)_{n f}=(1-\varphi)(\rho C p)_{f}+\varphi(\rho C p)_{n p}
\end{aligned}
$$

Where $\rho_{f}, \rho_{n f}$ are densities of the base fluid and nanoparticles, $\varphi$ represents volume fraction of nanoparticle, $\left(\rho c_{p}\right)_{n p}$ and $\left(\rho c_{p}\right)_{f}$ are heat capacities of nanoparticles and base fluid,respectively.

$$
\begin{aligned}
& K_{\text {eff }}=K_{\text {Brownian }}+K_{\text {Static }} \\
& \frac{K_{\text {Static }}}{K_{f}}=\left[\frac{\left(K_{n p}+2 K_{f}\right)-2 \phi\left(K_{f}-K_{n p}\right)}{\left(K_{n p}+2 K_{f}\right)+\phi\left(K_{f}+K_{n p}\right)}\right] \ldots(8) \\
& K_{\text {Brownian }}=50000 C p_{f} \varphi \rho_{f} \beta \sqrt{\frac{k_{b} T}{2 \rho_{n p} R_{n p}}} f(T, \varphi)
\end{aligned}
$$

Where;

$f(T, \varphi)=(0.28217+0.003917)\left(\frac{T}{T_{o}}\right)+(0.03669 \varphi-0.00339112)$

$\mathrm{T}$ is the fluid temperature, $K$ is the Boltzman constant and $T_{0}$ is the reference temperature, $\beta$ values of two types nanoparticles with their boundary conditions are illustrated in Table 1.

Table 1,

$\beta$ values of of $\mathrm{CuO}$ and $\mathrm{ZnO}$ nanoparticles material [14].

\begin{tabular}{llll}
\hline Nano particles & $\boldsymbol{\beta}$ & Concentration & Temperature (K) \\
\hline $\mathrm{CuO}$ & $9.881(100 \phi)^{-0.9446}$ & $1 \% \leq \phi \leq 6 \%$ & $298 \leq \mathrm{T} \leq 263$ \\
$\mathrm{ZnO}$ & $8.4407(100 \phi)^{-1.07304}$ & $1 \% \leq \phi \leq 7 \%$ & $298 \leq \mathrm{T} \leq 263$ \\
\hline
\end{tabular}

The effective viscosity can be obtained by using the following mean empirical correlation [15]:

$$
\frac{\mu_{e f f}}{\mu_{f}}=\frac{1}{\left(1-34.87 \varphi^{1.03}\left(d p N \pi \rho_{f o} / 6 M\right)^{-0.3}\right)}
$$

Where;

$\mathrm{M}$ is the base fluid molecular weight,

$\mathrm{N}$ is the Avogadro number

$\rho_{\text {fo }}$ base fluid density

2.4. Grid testing and codes validation

Finite volume was used to solve the equations of continuity, momentum and energy with their corresponding boundary conditions. The turbulences model was very important to describe the flow characteristics for each application. The standard k- $\varepsilon$ turbulence model and the Renormalized Group (RNG) k- $\varepsilon$ turbulence model were selected in order to reach accurate prediction for simulation. The Navier-Stokes equations with time-independent for incompressible turbulence model were solved for analysis. The SIMPLE algorithm was selected to evaluate the pressure field, the velocity profile at the inlet assumed as fully developed and the inlet turbulence intensity was selected as $1 \%$. Three different mesh spacing sizes $(0.01,0.02,0.03)$ was selected for grid size effect on Nusselt number values at 10000 Reynolds number including plain tube and trapezoidal ribs tube configurations. The results 
show that the mesh spacing of 0.01 give the optimum values of Nusselt number with maximum deviations up to $3 \%$ as elaborated in the Table 2.

Table 2,

Mesh dependence

\begin{tabular}{lcccll}
\hline Configuration & \multicolumn{3}{c}{ Mesh spacing size \% } & \multicolumn{3}{c}{ Nudeviations \% } \\
& 0.01 & 0.02 & 0.03 & 0.02 & 0.03 \\
\hline Plain tube & 89 & 87 & 86 & $2 \%$ & $3 \%$ \\
Trapezoidal ribs Tube & 115 & 113.5 & 111 & $1 \%$ & $3 \%$ \\
\hline
\end{tabular}

\section{Results and Discussion}

\subsection{Local and Average Nusselt Number}

The variations of the local Nusselt number versus position $\mathrm{x}$-direction of top wall and average Nusselt number for circluar tube with trapezoidal ribs and Reynolds number ranging from 10000 to 30000 using water as a working fluidare shown in Figures 4 and 5.Its be noted that the Nusselt number increases with the increase of the Reynolds number and the highest Nusselt number obtained at Reynolds number of 30000. This implies that The use of the ribs in the circular tube produce (i) good turbulence flow with good mixing after the ribs leading to thermal boundary layer desolation and (ii) the strong flow vortices conducte better mixing between the fluid near the tube wall and the tube center. The highest heat transfer enhancement was achieved for the trapezoidal ribs due to the increase of strong turbulence intensity.

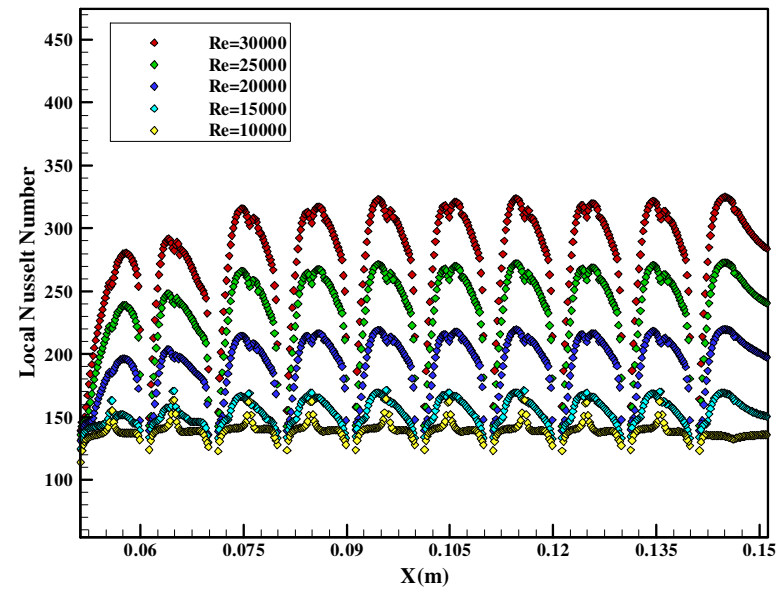

Fig. 4.Varation of local Nusselt number with $x$ position with trapzoidal ribs

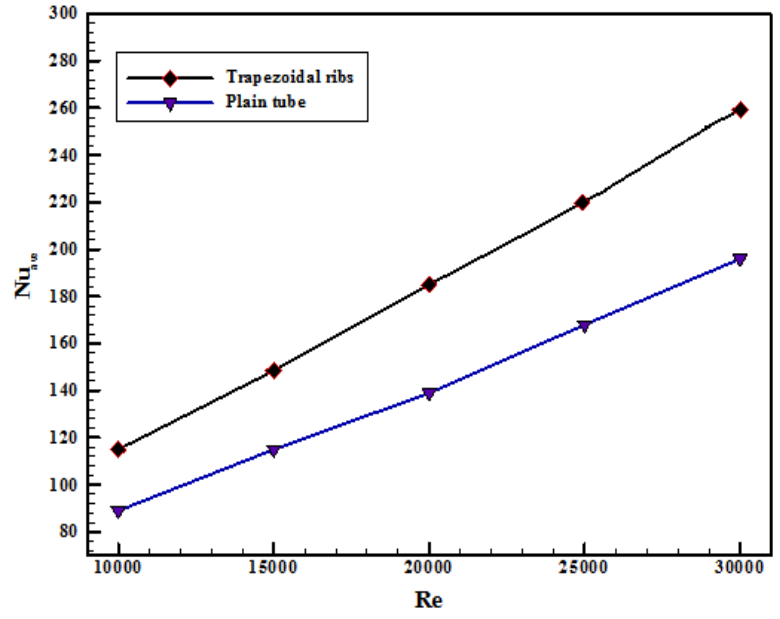

Fig. 5. Variation of average Nusselt number with trapezoidalat different Reynolds number.

\subsection{Skin Friction Factor}

The friction coefficient variations with Reynolds number for trapezoidal of ribs is presented in Figure 6. From this figure it is clearly seen that the skin friction factor constrict with Reynolds number the rises and maximum value of skin friction coefficient can be achieved by using trapezoidal ribs, whereas the minimum values of friction coefficient was found for smooth tube.

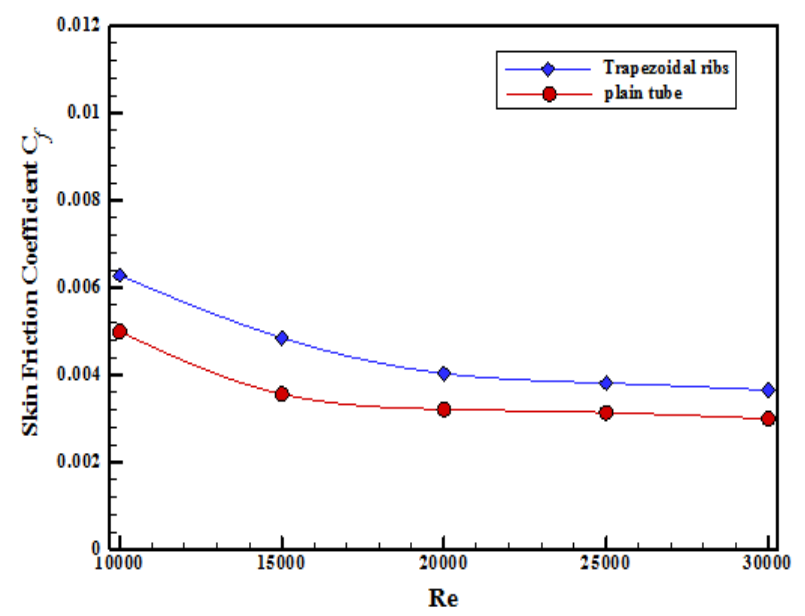


Fig. 6. Variation of skin friction coefficient with trapezoidal at different Reynolds number.

\subsection{The Effect of Nanoparticles}

Two types of nanoparticles namely $\mathrm{CuO}$ and $\mathrm{ZnO}$ with $2 \%$ volume fraction and pure water as base fluid for trapezoidal ribs were used in this investigation. The Nusselt number and skin friction friction versus different Reynolds number are shown in Figure.7 and 8.From Figure 7, its clearly noticed that the nanofluid Nusselt number was higher than that obtained by base fluid (water), this is result in due to the presence of nanoparticles increase of thermal conductivity and due to nanoparticles collision oneself and between the tube wall and nanoparticles, which increase the energy rate exchange. Among test fluids, it is clearly noted that $\mathrm{ZnO}$ nanofluid offered highest Nusselt number, followed by $\mathrm{CuO}$ and pure water, respectively. This is due to the lower thermal conductivity of $\mathrm{ZnO}$ as compared with $\mathrm{CuO}$ nano fluids, From Figure 8, its clearly seen that the friction factor decreases with the rising of the Reynolds number, while no effect was distinguish with different nanofluids.

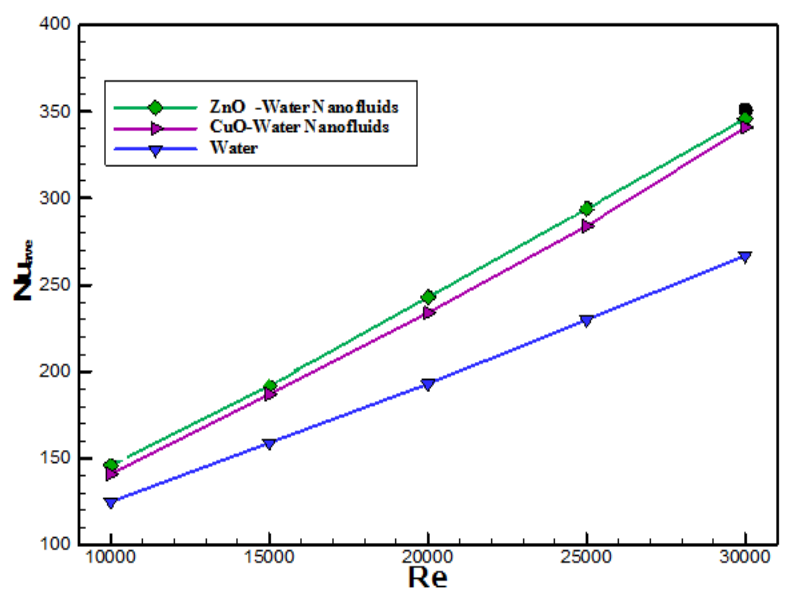

Fig. 7. Variation of average Nusselt number for pure water and different nanofluids types with trapezoidal ribs.

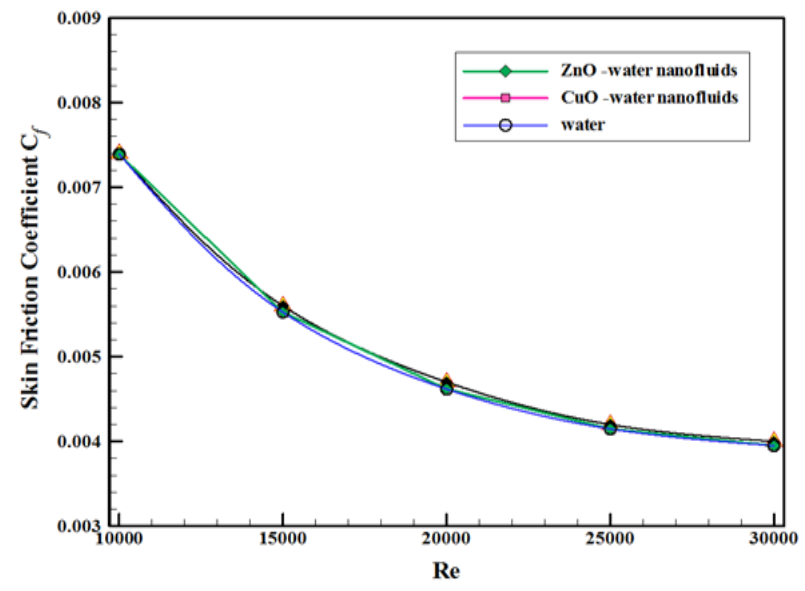

Fig. 8. Skin friction factorvariation of for pure waterand different nanofluids types with trapezoidal ribs

\section{Conclusions}

Forced convection for turbulent flow heat transfer simulation in a constant heat flux tube with trapezoidal ribs configurations were carried out using FLUENT 6.3.26.The effect of this configuration with aspect ratio of $\mathrm{p} / \mathrm{d}=5.72$ with water, $\mathrm{CuO}$ and, $\mathrm{ZnO}$ nano fluids with $2 \%$ volume fractions as a single-phase model were reported for Reynolds number variation from 10000 to 30000. The results in forms of heat transfer coefficient $(\mathrm{Nu})$ and skin friction factor (f) are reported as follow;

- The local and average Nusselt number are augmented for trapezoidal ribs tube than that of the plain tube and maximum Nusselt number was obtained with Reynolds number equal to 30000 , while the maximum friction factor obtained at Reynolds number equal to 10000.

- The $\mathrm{ZnO}$ nanofluid gives highest values of Nusselt number and skin friction factor, followed by $\mathrm{CuO}$ and pure water gives the lowest values of Nusselt number. However no effect was distinguish with different nanofluids and pure water. 


\section{Nomenclature}

$\begin{array}{ll}\mathrm{k}_{\mathrm{eff}} & \begin{array}{l}\text { Thermal conductivity in Energy } \\ \text { equation, W/m K }\end{array} \\ \mathrm{Re} & \text { Reynolds number, dimensionless } \\ \mathrm{Nu} & \text { Nusselt number, dimensionless } \\ \mathrm{p} & \text { Pressure, } \mathrm{N} / \mathrm{m} 2 \\ \mathrm{u} & \text { Velocity } \mathrm{m} / \mathrm{s} \\ \mathrm{T} & \text { Temperature. }{ }^{\circ} \mathrm{C} .\end{array}$

\section{Greek symbols}

$\begin{array}{ll}\stackrel{\rho}{\tau_{\text {eff }}} & \text { Density, } \mathrm{Kg} / \mathrm{m}^{3} \\ \text { Stress, } \mathrm{N} / \mathrm{m}^{2} .\end{array}$

\section{Acknowledgment}

We wish to specially acknowledge the assistance offered by the University of Baghdad AL Khwarizmi College of Engineering for carrying our this investigation.

\section{References}

[1] O. Manca, S. Nardini, D. Ricci, A numerical study of nanofluid forced convection in ribbed channel, Applied Thermal Engineering 37 (2012) 280-292.

[2] M. Chandrasekar, S. Suresh, A. Chandra Bose, Experimental studies on heat transfer and friction factor characteristics of $\mathrm{Al2O} /$ water nanofluid in a circular pipe under laminar flow with wire coil inserts, Experimental Thermal and Fluid Science 34 (2010) 122-130.

[3] C.Y. Tsai, H.T. Chien, P.P. Ding, B. Chan, T.Y. Luh, P.H. Chen, Effect of structural character of gold nanoparticles in nanofluid on heat pipe thermal performance, Materials Letters 58 (2004) 1461-1465.

[4] M.S. Liu, M.C. Lin, C.Y. Tsai, C.C. Wang, Enhancement of thermal conductivity with $\mathrm{Cu}$ for nanofluids using chemical reduction method, International Journal of Heat and Mass Transfer 49 (2006) 3028-3033.

[5] E. Tamjid, B.H. Guenther, Rheology and colloidal structure of silver nanoparticles dispersed in diethylene glycol, Powder Technology 197 (2010) 49-53.

[6] S.M.S. Murshed, K.C. Leong, C. Yang, Enhanced thermal conductivity of $\mathrm{TiO} 2-$ water based nanofluids, International Journal of Thermal Sciences 44 (2005) 367-373.

[7] H. Zhu, C. Zhang, S. Liu, Y. Tang, Y. Yin, Effects of nanoparticles clustering and alignment on thermal conductivities of Fe3O4aqueous nanofluids, Applied Physics Letters 89 (2006) 1-3.

[8] J.A. Eastman, S.U.S. Choi, S. Li, L.J. Thompson, Enhanced thermal conductivity through the development of nanofluids, Proceedings of the Symposium on Nanophase and Nanocomposite Materials II, vol.457, Materials Research Society, USA, 1997, pp. 3-11.

[9] M.E. Meibodi, M. Vafaie-Sefti, A.M. Rashidi, A. Amrollahi, M. Tabasi, H.S. Kalal, Simple model for thermal conductivity of nanofluids using resistance model approach, International Communications in Heat and Mass Transfer 37 (2010) 555-559.

[10] M.A. Ahmed, N.H. Shuaib, M.Z. Yusoff, A.H. Al-Falahi, Numerical investigations of flow and heat transfer enhancement in a corrugated channel using nanofluid, International Communications in Heat and Mass Transfer 38 (2011) 1368-1375.

[11] H.A. Mohammed, A.N. Al-Shamani, J.M. Sheriff, Thermal and hydraulic characteristics of turbulent nanofluids flow in a rib-groove channel, International Communications in Heat and Mass Transfer 39 (2012) 1584-1594.

[12] B.H. Salman, H.A. Mohammed, A. Sh. Kherbeet, Heat transfer enhancement of nanofluids flow in microtube with constant heat flux, International Communications in Heat and Mass Transfer 39 (2012) 11951204.

[13] M. Corcione, Heat transfer features of buoyancy-driven nanofluids inside rectangular enclosures differentially heated at the sidewalls, International Journal of Thermal Sciences 49 (2010) 1536-1546.

[14] R.S. Vajjha, D.K. Das, "Experimental determination of thermal conductivity of three nanofluids and development of new correlations", International Journal of Heat and Mass Transfer, vol. 52, Issues 21-22, pp. 4675-4682, 2009.

[15] M. Corcione,"Heat transfer features of buoyancy-driven nanofluids inside rectangular enclosures differentially heated at the side walls", International Journal of Thermal Sciences, vol. 49, Issue 9, pp. 1536-1546, 2010. 
[16] Jung-Yang San (2006), Wen-Chieh Huang "Heat transfer enhancement of transverse ribs in circular tubes with consideration of entrance effect" International Journal of Heat and Mass Transfer 49 p 2965-2971

[17] Maiga, S. E. B., S. J. Palm, C. T. Nguyen, G. Roy and N. Galanis (2005). "Heat transfer enhancement by using nanofluids in forced convection flows." International Journal of Heat and Fluid Flow 26(4): 530-546.
[18] Usui, H., Y. Sano, Iwashita, K. \&Isozaki, A. 1996. Enhancement of Heat Transfer by a Combination of Internally Grooved Rough Tube and Twisted Tape. International Chemical Engineering 26(1): 97-104 


\title{
دراسة عددية للتدفق الحراري للموائع في الأنبوب ذي النتوعات
}

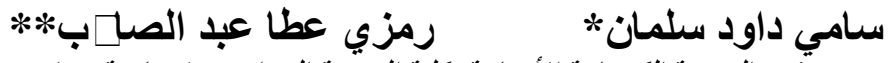

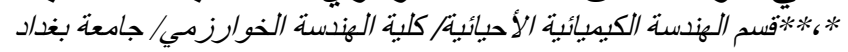

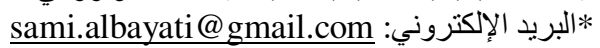

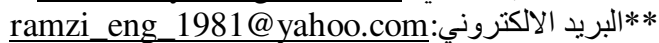

\section{الخلاصة}

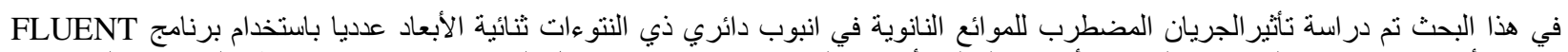

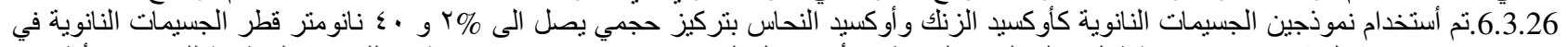

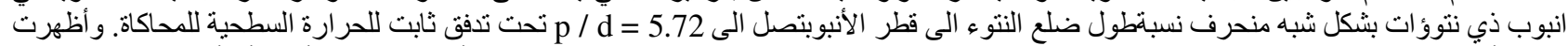

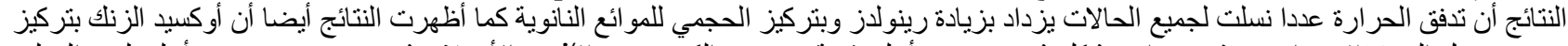

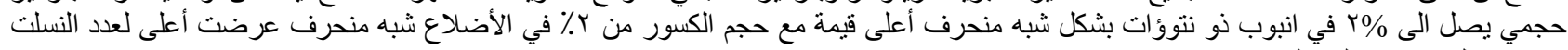

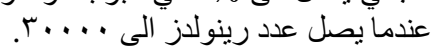

